\title{
Smallholder Farmers' Perception and Adaptation Strategies to Climate Change and Variability in Ankesha Guagusa District of Awi Zone, North Western Ethiopia
}

\author{
Addisu Kebede Tessema \\ Ethiopian Environment and Forest Research Institute, P.O. Box 24536, Addis Ababa, Ethiopia
}

\begin{abstract}
Agriculture is the main source of livelihood for rural communities in Ethiopia which is highly sensitive to Climate change and variability. Farmers should adapt and their decision to adapt depends on their perception to climate change and variability and other socio-economic factors. The main objective of this study was to assess smallholder farmers' perception, identifying the major adaptation strategies and determinant factors that affect farmers' choices of adaptation to climate change and variability in Ankesha Guagusa district, Awi Zone, Ethiopia. Descriptive statistics were employed to assess farmers' socio- demographic characteristics, perceptions and adaptation measures. A Multi-Nominal Logit model (MNL) was also used to identify the determinant factors that influence the choice of farmer's adaptation strategies. The study finds that, most of the local farmers perceived decreasing in the amount of seasonal rainfall, increasing in temperature, increased frequency of drought and flood. In response to these impacts of climate change and variability; farmers used crop diversification, improved and early maturing crops, planting trees and engaging on off-farm activities, credit and taking loss as the most dominant adaptation strategies. The MNL regression analysis showed that agro ecology of woina dega (AEZWD), age, sex, education, family size, farm size, farming experience, income, livestock holding (TLU), access to extension services, credit, access to irrigation and water harvesting schemes and Perception to climate change and variability were the key determinant factors influencing farmers' choice of adaptation strategies to climate change and variability. farmers' adaptive capacity is hindered by different factors and focusing on addressing these factors efforts should be made to develop and implement integrated policies and strategies that enhance access to income and farm inputs, agricultural extension services, livelihood diversification, farmers' awareness on climate change required to build resilience of communities and promote a transition to climate-smart agriculture.
\end{abstract}

Keywords: Climate Change and variability, Perceptions, Adaptation Strategies, Determinants, MNL model, Ethiopia

DOI: $10.7176 / \mathrm{JRDM} / 58-02$

Publication date: August $31^{\text {st }} 2019$

\section{Introduction}

Climate change and the associated weather extremes have continued posing serious challenges to our planet. Despite the fact that, significant debates remain over the extent to which humans have induced climate change (WMO 2007). The United Nations Environment Programme (UNEP) report has also shown that, many of the continental regions have experienced a sharp seasonal and annual rainfall and temperature variations plus with extreme events; such as flood, storms and drought. Observable trends of ongoing climate change and current projections indicate increasingly severe negative impacts on the majority of countries disproportionately affecting developing countries (Leta 2011). Ethiopia is one of the developing counties in which agriculture is the main source of its economy, which accounts for about $50 \%$ of the country's gross domestic product (GDP), generates $90 \%$ of export earnings and supplies about $70 \%$ of the country's raw material to the secondary activities (MOFED 2006). It is a major source of income and subsistence for the nation and it plays a great role in sustainable economic growth and development. As a result, the issues of climate change stands at the heart of Ethiopian transformation agenda. This shows how much the country is vulnerable to the impacts of climate change and variability. To reduce such impacts of climate change and variability on food supplies, livelihood and economies, we must greatly increase adaptive capacity in agriculture both on long term climatic trends and to increasing variability as an urgent policy to achieve the overall objectives of Ethiopian growth and transformation plan (Kide 2014). Adaptation is an essential strategy to enable farmers to cope with the adverse effects of climate change and variability which in turn increases the agricultural production of farm households. So it is important to have a full understanding of farmers' perception and their adaptation methods to tackle the challenges of climate change and variability and to develop appropriate adaptation measures and policies.

Some research attempts have been done to investigate farmers perception and adaptation to the impacts of climate change and variability at national and global level and it is shown that local community based adaptation practice is an urgent issue particularly in developing countries. However, such studies at local scale are very scanty and little is known about local communities' perception of climate change and adaptation to it. Therefore, the aim of this study was to examine smallholder farmers' perception, to identify the major adaptation strategies and 
determinant factors that affect farmers' choices of adaptation to climate change and variability in Ankesha Guagusa district.

\section{Materials and Methods}

\section{Description of the study area}

The study was carried out in Ankesha Guagusa district of Awi zone whch is located in the north western part of Ethiopia, approximately $480 \mathrm{~km}$ North West of Addis Ababa, the capital city; $120 \mathrm{~km}$ south west of Bahir Dar, the capital city of the region and $17 \mathrm{~km}$ South-West of Injibara; the administrative town of Agew Awi Zone. Its absolute location extends between the coordinates of $10^{\circ} 31^{\prime} 46^{\prime \prime}$ and $10^{\circ} 41^{\prime} 32^{\prime \prime}$ 'north latitude and $36^{\circ} 36^{\prime} 18^{\prime \prime}$ and $36^{\circ} 59^{\prime} 33^{\prime}$ ' east longitude (Figure 1). It is bordered on the north by Banja shekudad, on the south by Mirab Gojjam, on the east by Guagusa Shekudad and on the west by Guangua district. Its elevation varies from 1500-2800 m.a.s.l. it has three agro climatic zones; dega, woina dega and kola. The resulting weather pattern provides the highlands with most of its rainfall during a period that generally lasts from May to mid-September. Based on the 2007 national census conducted by the Central Statistical Agency of Ethiopia (CSA), this district has a total population of 199,826, of whom 99,285 are men and 100,541 women. The farming system is characterized by a smallholder mixed agriculture for which land and livestock are the most important livelihood assets.

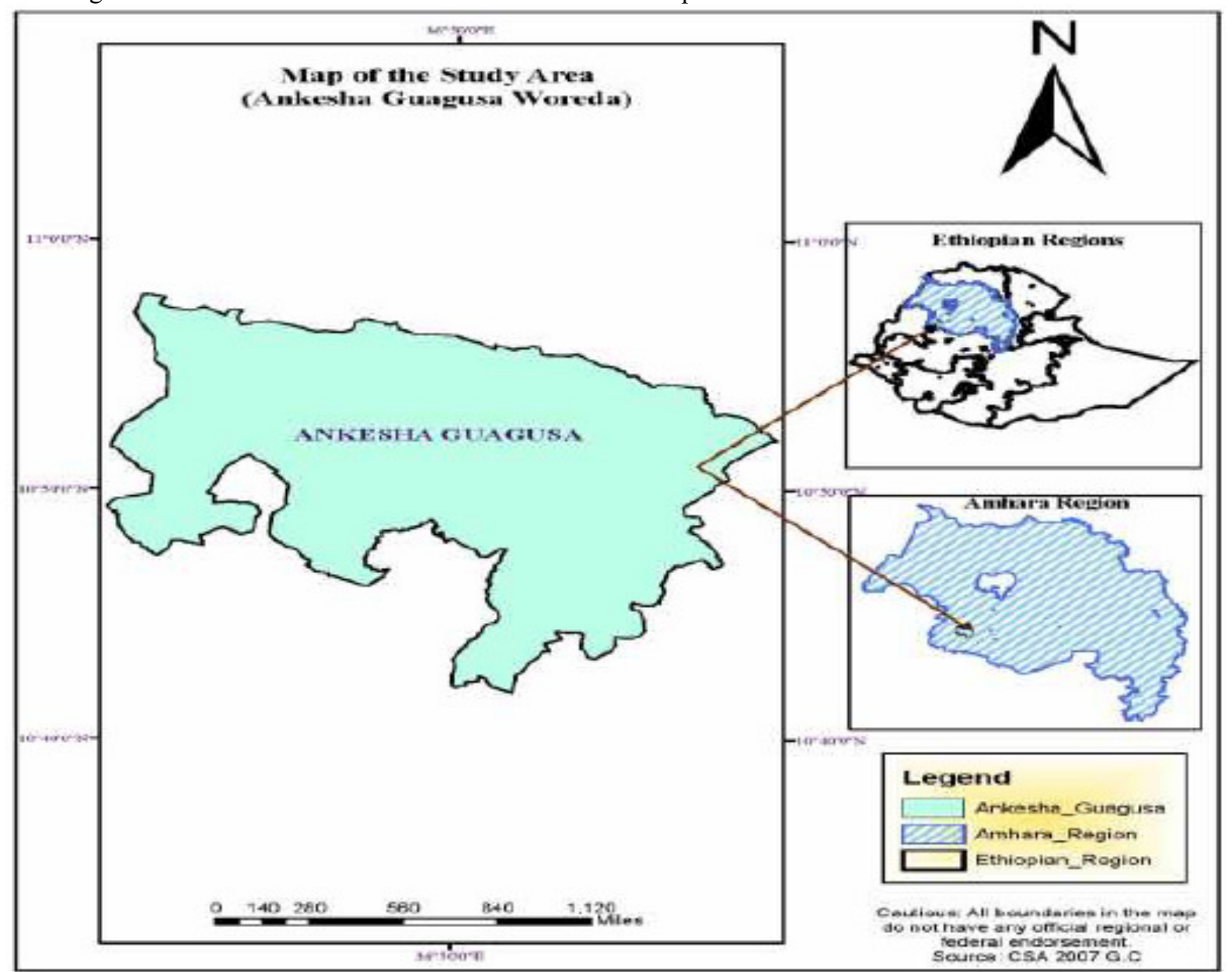

Figure 1. Map of the study area

\section{Sampling Design}

This study followed a multi-stage stratified random sampling where a combination of purposive (to select sample Kebeles) and random sampling (to select sample households) were used. In the first stage, Ankesha Guagusa district was purposively selected because it is one of the most severely affected districts by climate change and weather extremes. In the second stage, the district was classified into three strata according to the traditional climatic zone classification system as Lowland (kola), Midland (woyna-dega) and Highland (dega) agro-ecological zones. From each agro-ecology, one target kebele was selected purposely to capture variations across different agro-ecologies. Accordingly, Dugili, Sostu G/bet, and Bekafta kebeles were selected from the three agroecological zones respectively. In the third stage, sample households were selected from each target kebele using simple random sampling (SRS) and sample size was determined proportionately and a total of 150 sample 
households were selected and contacted to get information required for the study.

\section{Data sources and collection methods}

The study used both quantitative and qualitative data generated from primary and secondary data sources. The primary data were obtained from primary sources; such as field observation, household survey, government officials and local administrative authorities. Data on socio-economic, perception of households about climate variability and change and local adaptation mechanisms were collected by administrating questionnaires prepared normally in English and translated in to their respective Amharic meaning for effective communication with the three groups of selected interviewees; sample households, key informants and FGD members. The climatic data were also obtained from the National Meteorological Services Agency (NMSA) and crop production data were obtained from the district's agricultural office. In household survey, farmers were asked to evaluate long-term changes in rainfall intensity and duration, mean temperature, extreme climatic events and their adaptation methods. Three focus group discussions (FGDs) and three key informant interviews were conducted in each target kebele. The individuals who participated in the FGD were knowledgeable, fairly represent and reflect the opinion of the community at large. In-depth Interviews were also held with local elders, agricultural experts and other governmental offices in order to get relevant and reliable information.

secondary data were collected from various sources; including previous scientific studies and reports from district level agricultural bureau and other concerned organizations, reviewing different relevant literature from books, research works, journals, published and unpublished documents and different activity reports of government and non-government institutions.

\section{Methods of data analysis}

Data obtained from primary and secondary sources were analyzed using descriptive statistical methods and used to summarize the data on farmers perception, adaptation strategies and factors determining the choices of adaptation strategies. A multinomial logit (MNL) model was also used to analyze the determinants of farmers' adaptation options to climate change and variability by using SPSS version 23. Due to the computational draw backs of multinomial probit (MNP), multinomial estimation is appropriate as it exhibits superior ability to predict discrete choices (Mohammed 2007). The MNL model requires that households are associated with only their most preferred option from a given set of adaptation strategies. Unbiased and consistent parameter estimates using this model need to assume independence of irrelevant alternatives that requires that the probability of using a certain adaptation method by a given household is independent from the probability of choosing another adaptation method. We are aware that collecting and using only the most preferred adaptation option for each household risks underemphasizing the known importance to smallholder farmers of using multiple adaptation strategies. The generalized form of probabilities for an outcome variable with $j$ categories is:

$$
\operatorname{Pr}\left(y_{i}=j \mid x\right)=p r_{i j}=\frac{\exp \left(x^{\prime} \beta j\right)}{1+\sum_{\substack{j=2 \\ \text { For } j>1}}^{j} \exp \left(x^{\prime} \beta j\right)}, \quad j=1,2 \ldots J
$$

The parameter estimates of the MNL model only provide the direction of the effect of the independent variables on the dependent (response) variable; estimates represent neither the actual magnitude of change nor the probabilities (Dasgupta et al. 2014; Greene 2000 cited in Belay et al. 2017).

\section{Results and Discussions}

\section{Demographic and Socio-Economic characteristics of sample households}

Some demographic and socio-economic data were gathered through household survey. Table 1 below shows the major characteristics of the sample households. It is shown that, 53\% of the sample households were males and the remaining $47 \%$ were females. The average age of respondents was 43 years with a standard deviation of 14.1 years. Regarding education, $21 \%$ were illiterate, $79 \%$ of the respondents can read and write.

Table 1. Socio-demographic characteristics of sample households

\begin{tabular}{|c|c|c|c|c|}
\hline \multicolumn{2}{|c|}{$\operatorname{Sex}(\%)$} & Average Age (years) & \multicolumn{2}{|c|}{ Educational status (\%) } \\
\hline Male & Female & & illiterate & can read and write \\
\hline 53 & 47 & & 21 & 79 \\
\hline
\end{tabular}

The average family size was 5.7 with a standard deviation of 2.15 and the result is greater than the national average 5.1 persons per household (Arragaw and Woldeamlak 2017). The size of land owned by a household ranges from 1 kada to 12 kada with an average farm size of 6 kadal equivalent to 1.5 ha which is greater than the national average of 1 ha (CSA 2008 cited in Adimassu and Kessler 2016). Occupationally, 97\% of the respondents 
are farmers and 3\% are traders. The Farming system of the study area is mixed farming which includes crop production and livestock rearing. Crop farming is the main source of income for $89 \%$ of the respondents and mixed farming is the main source of income for $11 \%$ of the respondents. Majority of the respondents involved in crop production and dependent on rain fed agriculture.

\section{Rainfall and temperature variability and trends}

Statistical analysis of over 32 years of meteorological data shows that, rainfall and temperature values have shown significant variations and climatic shocks have been increasing in the last three decades. The inter-annual and seasonal rainfall variability is high and erratic on annual time scale. Seasonal rainfall is slightly decreasing and its variability is strongly associated with late onset and early offset of the rainy season. The short rainy season (MarchMay, known as Belg) rainfall is more variable than that of main rainy season (June-September, known as Kiremet) rainfall. From the historical rainfall data, the year 2002 was the driest year and year 2012 was the wettest year in the area over the period of record (1983-2014). The temperature of the study area was also characterized by general trends of increase and shows inter annual variability. The average annual temperature is also increasing by $0.27 \mathrm{oC}$ every decade which is higher than the national average $(0.23 \mathrm{oC})$. Though, the degree differs, the occurrence of weather events is consistent with that of Ethiopia; farmers already suffer from extremes of climate manifested in the form of frequent drought and flood. In addition to these a number of climatic hazards occurred in the study area such as shifting in the timing of rainfall and shortened period of rainy season, unseasonal rainfall, frost, Pests, diseases and the rainfall pattern has become unpredictable as a result of climate change and variability.

\section{Farmers' perceptions of climate change and variability and its impacts}

Increasing awareness of risks associated with climate change and variability among smallholder farmers is critical in building their capacity to develop the necessary adaptive measures. In the survey, farmers were asked to tell what they perceived to changes in temperature and rainfall in the study area over the last couple of decades. $83 \%$ of respondents perceived increase in temperature, $6 \%$ of respondents perceived that temperature was declining and $11 \%$ of the respondents perceived no change in temperature. In terms of rainfall, $79 \%$ of the respondents perceived a decrease in the amount of seasonal rainfal1, $5 \%$ of the respondents perceived increase in the amount of seasonal rainfall and $16 \%$ noticed no change in the amount of rainfall. Respondents told that, the frequency of drought and flood are increasing, a general delay in onset of rains and the rainfall distribution pattern is becoming unpredictable. This was supported by the analysis of meteorological data which showed a declining trend of seasonal rainfall, increased frequency of drought and increasing temperature.

Regarding the impacts of climate change and variability, the frequently experienced climatic shocks identified by the respondents that have a significant impact on crop production are prolonged drought including late on set/early off set of rain, flood, frost and unseasonal rainfall. From the annual crop data analysis, there was a frequent decline of crop production in the district from 2002-2009. The respondents listed a number of reasons for this production decline. Out of the total $68 \%$ of the respondents said climate variability, $31 \%$ declining soil

fertility, $15 \%$ lack of input and $7 \%$ crop pest found to be the major reasons for yield reduction (Figure 2 )

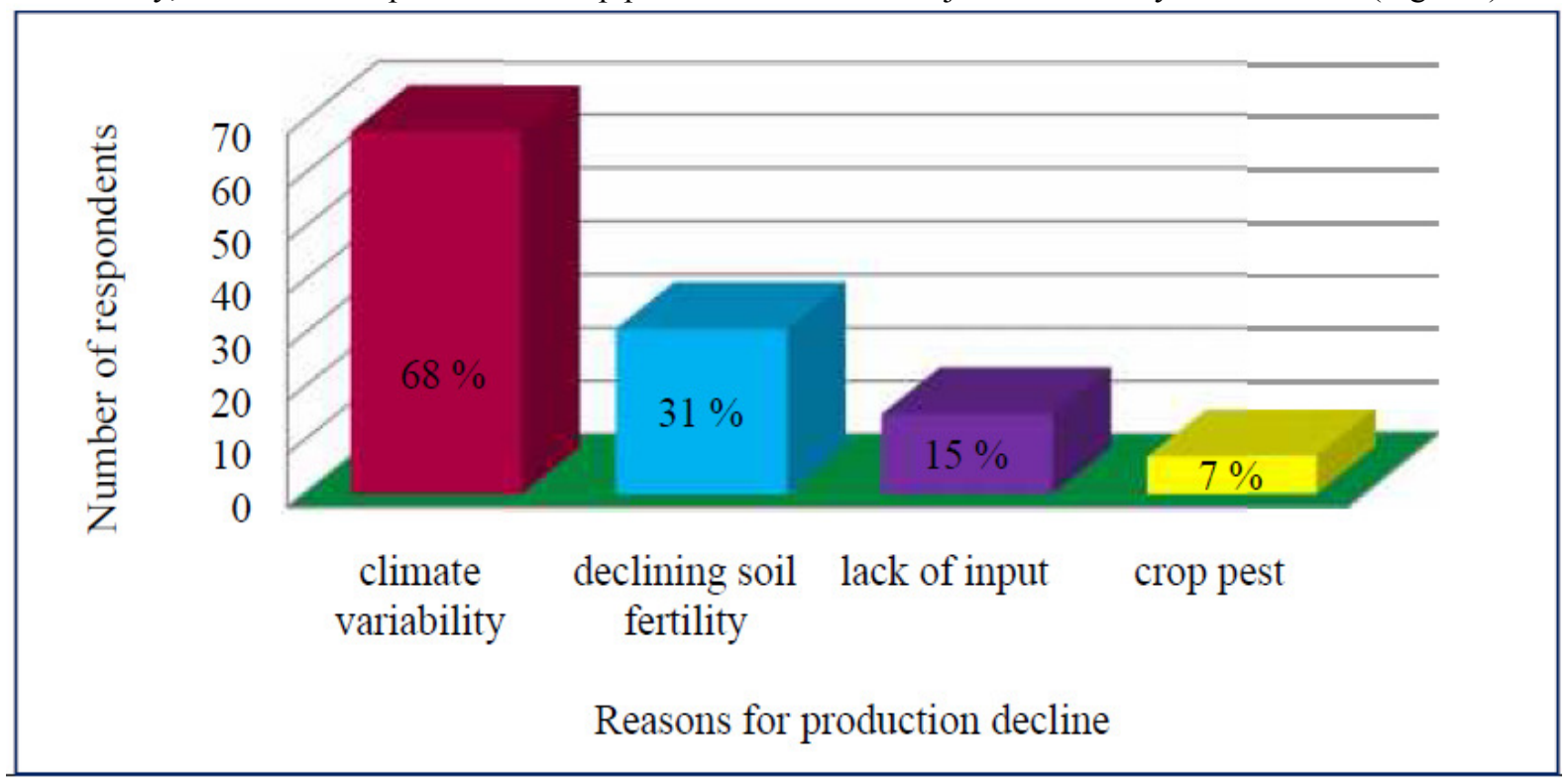

Figure 2 Perception of farmers for decline in crop production from 2002-2009

Even though, statistically significant differences exist between percentages of respondents noticed each 
climatic change across agro-ecological zones, the same types of climatic changes were mentioned in all agroecological zones. Based on the analysis of statistical data of temperature and rainfall and participants responses, the researcher argued that, majority of the respondents have perceived climate change and variability and its impact in the study area.

\section{Local adaptation strategies to climate change and variability}

Climate change poses significant challenges on households, businesses and governments and it is responded by climate change mitigation and adaptation. In contrast to climate change mitigation, which requires cooperation at a global level, most climate change adaptations occur at a local level through the actions of individuals and communities in response to locally specific climate change impacts. One of the intended objectives of this study was to identify some of major adaptation strategies practiced by local farmers in response to the impacts of climate change and variability. Farmers in the study area are using various adaptation strategies to reduce the impacts of climate variability and change. According to the survey conducted in Ankesha Guagusa district, the major adaptation strategies include crop diversification, improved and early maturing crops, planting trees and engaging on off-farm activities, credit and taking loss (Figure 3) below.

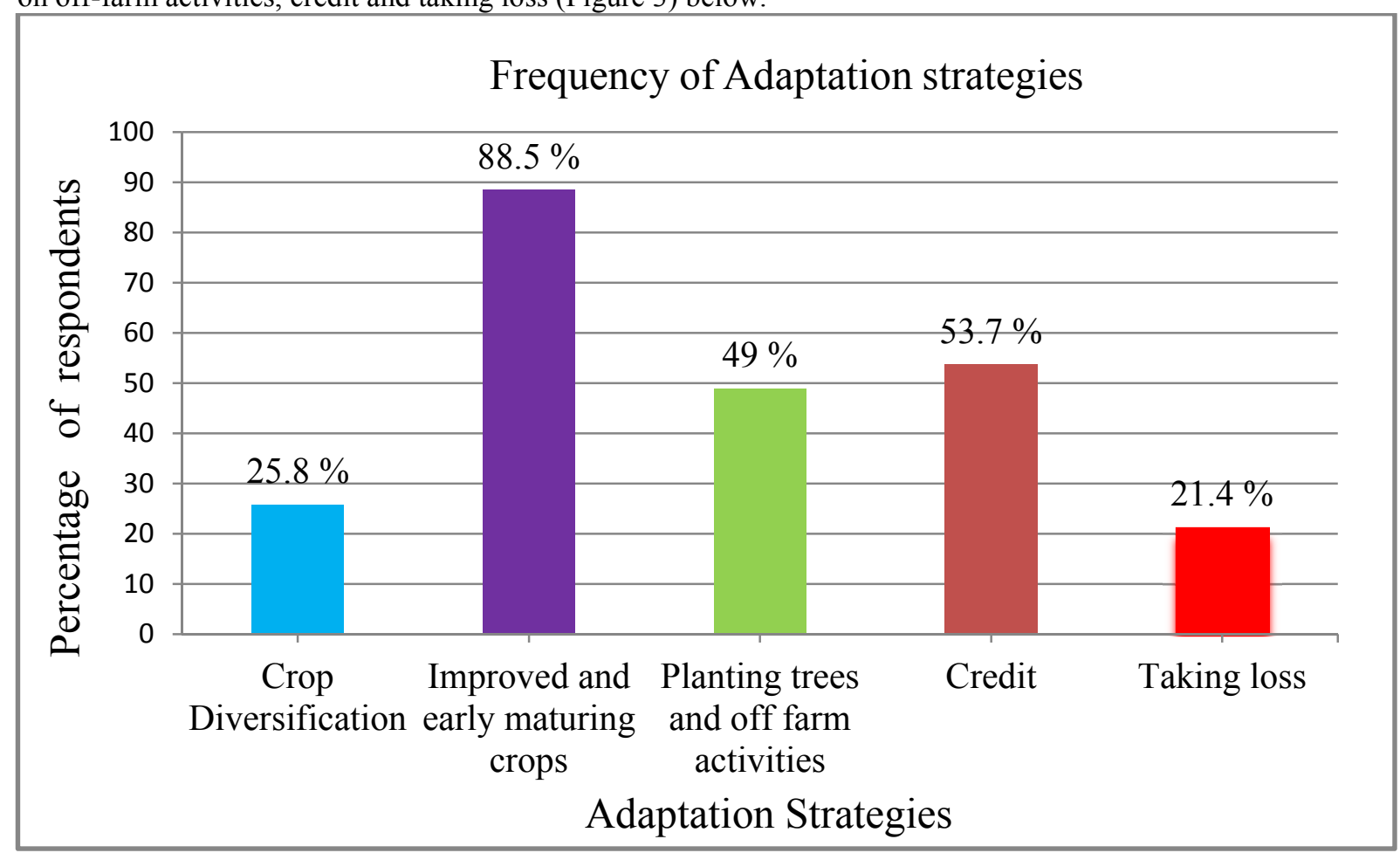

Figure 3 Major Adaptation strategies of Ankesha Guagusa district

As indicated in Figure 3 above, using improved and early maturing crops that accounts for $88.5 \%$ of the respondents was one of the predominant adaptation strategies in the area to reduce the risk of crop failure that usually associated with late onset and early off set of rainfall. Before the past three decades, the area was productive in cereal crops and pulses but now because of fluctuation of rainfall and shortening of growing season, the crop types are changed from late maturing to early maturing. These crops require minimum moisture to grow and low input demand, as a result it is considered as the most important adaptation strategy. The agricultural office of the district supplies improved seed varieties of maize and wheat that adapts and tolerates the climate of the area and trains farmers on how to use these seeds and the inorganic fertilizer in the field so as to increase the production of crops and reduce food shortage.

The second adaptation strategy used in the area is credit as indicated by $53.7 \%$ of the respondents from betteroffs, informal social organizations and government institutions. Since few years Amhara Credit and Saving Institution is also providing credits to help farmers buy agricultural inputs, livestock and create an asset. As learned from the farmers and credit association managers, the farmers organize themselves so that the members are responsible for individual's credit. The credit is granted during the months of February and March in the time of preparation for main farming and the time for paying back is after crops are harvested each year and this is supported by (Temesgen 2008) who stated that availability of credit eases the cash constraints and allows farmers to buy purchased inputs such as fertilizer, improved crop varieties and irrigation facilities.

Planting trees and engaging on off-farm activities is the third most significant adaptation strategy from which $49 \%$ of the respondents took advantage of it. Planting trees; especially eucalyptus trees (E. globulus and E. 
camaldulensis) and black wattle or early green wattle (Acacia decurrens) on their farm and mountainous areas is used for sale of firewood, house construction and used a source of income during the time of climatic crisis. After planting trees on their farm; they engaged on off-farm activities which are additional works other than farming used by local people to increase their income and to compensate the amount of earnings lost due to decreased agricultural production and helps households to retain assets or to withstand climatic shocks. They are diverse and include petty trading, wood sell, daily laboring, shopping, weaving and construction activities. This is in line with (Temesgen 2008) in which $21 \%$ of of the farmers used as an alternative adaptation measure.

Crop diversification is another adaptation strategy employed in the area and it is growing of two or more crops in the same field. $25.8 \%$ of Farmers have a good experience of mixing crops in the field; teff with early maturing sorghum, maize with bean and in most cases cereals with legumes plants are grown together. From discussions with farmers, it was noted that, they have wide knowledge on advantages of mixing crops with varying attributes in terms of maturity period, drought tolerance and end use of the products to diversify the income source of the households. This is in agreement with (Belay et al. 2017) in which 23\% of the households used as the main adaptation strategy.

According to the survey, $21.4 \%$ of the respondents do not undertake any adaptation strategy to the impacts of climate related hazards and they accept loss and this is consistent with the study of (Leta 2011) in which $17.7 \%$ of farmers do not undertake any action to cope up with weather related hazards. This is due to inability of the farmers to respond and when they have no choice. There was no statistically significant difference in adopting one adaptation option across agro-ecological zones and farmers from each agro-ecological zones shared common adaptation strategies.

As discussion held with district agricultural experts, local farmers are also using changing their planting dates, using irrigation, digging water wells, using fertilizer, saving, implementing water and soil conservation methods, terracing and reforestation. In general, the magnitude and rate of current climate shocks combined with additional socio-economic issues are making many community's owned adaptation mechanisms ineffective and the study has established that, the existing adaptation mechanisms are not enough to adapt the contemporary impacts of climate variability and change and there should be intervention in developing effective and feasible adaptation strategies.

\section{Barriers to climate change adaptation}

Different socio-economic and environmental factors hindered the adoption of adaptation measures in the study area. Some of these are lack of financial capital and poverty, Shortage of farmland to intensify agricultural production, low potential for irrigation and lack of education and training on appropriate adaptation strategies contributed to low adaptive capacity of farmers. Temesgen (2008) found similar result in the analysis of barriers to adaptation to climate change in the Nile basin of Ethiopia which indicated five major constraints to adaptation and most of these are associated with poverty. Lack of money hinders farmers from getting the necessary resources and technologies which assist to adapt to climate change. Farmers in Ethiopia in general are very poor and cannot afford to invest on irrigation technology not only to adapt to climate change but also to sustain their livelihood during harsh climatic extremes such as drought which often causes famine. So the government should involve in awareness creation and provide training on locally effective adaptation strategies and strengthen institutions to support farmers to adapt to climate change and variability.

\section{Determinants of farmers' choices of adaptation strategies to climate change and variability}

A MNL model was used to estimate the determinants of farmers' choices of adaptation strategies to reduce the impact of climate change and variability. In this analysis, taking loss was used as a base category against which other groups compared. The likelihood ratio statistics indicated by the Chi-square was highly significant at $p<$ 0.001 , suggesting that the model has strong explanatory power. The explanatory variables that are hypothesized to influence farmers' choices of adaptation strategies to climate change and variability were demographic, socioeconomic and environmental factors while the dependent variables were those adaptation strategies that are chosen by the sample households. Regression coefficients, average marginal effect and their significance levels were used to see the probability of a particular choice of adaptation for a unit change in the independent variables.

Accordingly, a multinomial logit regression analysis of the factors influencing the choice of farmers' adaptation strategy in Table 2 below shows that agro ecology of woina dega (AEZWD), age, sex, family size (Famsi), farming experience (Farexp), access to extension services (Ext), farm size (Farsi), Irrigation (Irri) and Perception to climate change and variability (Per-ccv) are significantly and positively associated with crop diversification. On the other hand, education (educ), access to extension services and Perception to climate change and variability have positive and significant influence on growing improved and early maturing crops (IMPEMC). Farm size, income, education, livestock holding (TLU) and Perception to climate change and variability have significant and positive correlation with planting trees and off-farm activities (PTOFF). Similarly, income significantly and negatively influences the use of credit. In addition to these, livestock holding and Perception to climate change and variability showed negative relations with credit and taking loss respectively. Access to credit 
(credit) had no statistically significant effect on any of the selected adaptation strategies. Thus, one explanatory variable which is highly significant to affect the decision for a particular strategy may be insignificant for other adaptation strategy/ies with different levels of significance.

Table 2 Parameter estimates of the multinomial logit (MNL) model for adaptation strategies to climate change and variability

\begin{tabular}{|c|c|c|c|c|c|c|c|}
\hline \multicolumn{2}{|c|}{ Crop-diversification } & IMPEMC & PTOFF & \multicolumn{2}{|r|}{ Credit } & \multicolumn{2}{|r|}{ Taking loss } \\
\hline Variables & $5 \quad$ B $\quad$ Sig. $\operatorname{Exp~(B)~}$ & B $\quad$ Sig. $\quad \operatorname{Exp}(B)$ & B $\quad$ Sig. $\operatorname{Exp~(B)~}$ & B $\quad \mathrm{S}$ & Sig $\quad \operatorname{Exp}(B)$ & $\mathrm{B}$ & Sig. $\operatorname{Exp}(\mathrm{B})$ \\
\hline AEZWD & $2.360 .005 * 10.615$ & $\begin{array}{llll}0.912 & 0.14 & 0.402\end{array}$ & $0.1640 .775 \quad 0.848$ & 0.513 & 0.3840 .599 & 0.334 & $0.564 \quad 0.716$ \\
\hline Age & $18.40 .083 * * * 23.7$ & $\begin{array}{lll}18.233 & 0.996 & 9.87\end{array}$ & $\begin{array}{lll}19.25 & 0.995 & 4.363\end{array}$ & 38.542 & 0.8642 .049 & 17.65 & 0.9962 .147 \\
\hline Sex & $2.009 \quad 0.004 * 7.45$ & $\begin{array}{lll}0.624 & 0.321 & 1.867\end{array}$ & $\begin{array}{lll}0.480 & 0.433 & 1.615\end{array}$ & 0.608 & $0.221 \quad 1.837$ & 0.182 & $0.778 \quad 1.200$ \\
\hline Educ & $0.223 \quad 0.724 \quad 1.250$ & $2.52 \quad 0.01 * * * \quad 12.4$ & $4.0840 .000 * 59.3$ & 0.136 & $0.811 \quad 1.146$ & 2.576 & $0.61 \quad 13.143$ \\
\hline Famsi & $0.283 \quad 0.008 * \quad 0.76$ & $\begin{array}{lll}19.12 & 0.998 & 4.936\end{array}$ & $\begin{array}{lll}1.005 & 0.481 & 0.436\end{array}$ & 0.781 & 0.6732 .187 & 1.481 & $0.617 \quad 4.083$ \\
\hline Farsi & $0.910 .051 * * * 2.51$ & $\begin{array}{lll}0.405 & 0.765 & 1.500\end{array}$ & $0.98 \quad 0.004 * 0.203$ & 0.288 & 0.8580 .750 & 1.009 & $0.472 \quad 3.000$ \\
\hline Farexp & $2.98 \quad 0.017 * * 1.97$ & $\begin{array}{lll}36.78 & 0.996 & 9.434\end{array}$ & $\begin{array}{lll}0.020 & 0.875 & 0.851\end{array}$ & 0.693 & 0.7110 .500 & 0.250 & $0.825 \quad 0.017$ \\
\hline Income & $\begin{array}{llll}21.379 & 0.998 & 5.189\end{array}$ & $\begin{array}{lll}0.829 & 1.575 & 0.611\end{array}$ & $2.510 .057 * * * 13.6$ & -5390 & $0.047 * * 0.61$ & 38.54 & $0.997 \quad 1.827$ \\
\hline TLU & $\begin{array}{lll}0.375 & 0.559 & 1.455\end{array}$ & $\begin{array}{lll}1.297 & 0.481 & 0.093\end{array}$ & $1.620 .014 * 5.06$ & -0.038 & 0.9511 .039 & 17.89 & $0.998 \quad 1.694$ \\
\hline Ext & $0.003 * 7.94$ & $1.140 .07 * * * \quad 0.92$ & $\begin{array}{lll}0.954 & 0.157 & 0.385\end{array}$ & 0.421 & $0.497 \quad 1.524$ & 0.611 & $0.327 \quad 1.911$ \\
\hline Credit & $0.207 \quad 2.375$ & $\begin{array}{llll}0.057 & 0.924 & 0.944\end{array}$ & $\begin{array}{lll}0.693 & 0.235 & 0.500\end{array}$ & 1.083 & $0.104 \quad 0.339$ & 0.201 & $0.729 \quad 0.818$ \\
\hline Irri & $0.001 * 8.09$ & $\begin{array}{lll}0.544 & 0.468 & 1.723\end{array}$ & $\begin{array}{lll}36.783 & 0.99 & 9.434\end{array}$ & 0.077 & 0.9180 .926 & 0.223 & $0.764 \quad 1.250$ \\
\hline Per-ccv & $0.004 * 0.19$ & $1.60 \quad 0.019 * * 0.20$ & $3.347 \quad 0.000 * 0.35$ & 1.106 & $0.142 \quad 3.021$ & -0.122 & $\begin{array}{ll}0.870 & 1.129 \\
\end{array}$ \\
\hline
\end{tabular}

$*, * *, * * *$ indicates levels of significance at $1 \%, 5 \%$ and $10 \%$ probabilities respectively. Dependent variableadaptation; reference category: taking loss.

\section{Agro ecology of woina dega (AEZWD)}

Results of the MNL regression analysis show that farmers' living in woina dega is more likely to use cropdiversification at $\mathrm{p}<0.01$ and increases the probability using crop diversification as the main strategy 10.6 times greater than those households' living in dega and kola agro ecologies. This is consistent with the finding of (Belaineh et al. 2004; Atinkut and Mebrat 2016) who found that, rural households' living in the woina dega are more likely to adapt to changing situations than those in dega due to the existence of high variability in climate compared with dega households'. But this result contradicts with the finding of (Deressa et al. 2011) who argued that, farmers living in dega (highlands) perceived more change in climate than farmers in Kola (lowland) or Woinadega (mid-land).

\section{Age of the household head (Age)}

In Table 2, age is positively and significantly associated with crop diversification at $p<0.1$. A unit increase in the age of the household would increase the probability of using crop diversification by 23.7. this is in agreement with the study of (Hassan and Nhemachena 2008; Grace 2011) Who assumed that, old age is associated with more experience and expect older farmers to adapt to changes in climate than younger farmers.

\section{Sex of Household Head (Sex)}

Sex of household is significantly and positively correlated with crop diversification at $p<0.01$. Being male headed households' increase the probability of using crop diversification by 7.4 times greater relative to the base category. This is in line with the study of (Jiri et al. 2015) which stated that, Male headed households significantly improved chances of adopting agronomic practices; like, crop diversification.

\section{Education (Educ)}

Education is positively and significantly related with growing improved and early maturing crops and planting trees and off-farm activities (PTOFF) at $p<0.1$ and $p<0.01$ respectively. A unit increase in number of years of education could increase the likelihood of adopting by growing improved and early maturing crops and planting trees and off-farm activities by 12.4 and 59.3 respectively. Farmers with higher levels of education are more likely to better adapt to climate change. This is because educated farmers are expected to adopt new technologies based on their awareness of the potential benefits from the proposed climate change adaptation measures (Temesgen 2008).

\section{Family size (Famsi)}

The results in Table 2 show that, Family size has a significant and positive correlation with Crop-diversification at $p<0.01$. A one person increase in the family can increase the probability of using Crop diversification by 0.76 . Large family size is normally associated with a higher labour endowment and enable a household to accomplish various agricultural adaptations to climate change. Large families are able to practice multiple cropping whereas smaller ones tend to practice only mono-cropping with a livestock activity, whether under dry land or irrigation. 
This suggests that multiple cropping is more labor intensive (Hassan and Nhemachena 2008).

\section{Farm size (Farsi)}

Farm size has appeared to be significant and positively associated with crop diversification and planting trees and off-farm activities (PTOFF) at $\mathrm{p}<0.1$ and $\mathrm{P}<0.01$ respectively. A unit increase in the size of the farm in hectares per household increases the probability of using crop diversification by 2.5 and planting trees and off-farm activities by 0.5. this is in agreement with (Adimassu and Kessler 2016; Oremo 2013) which states that more land means more possibility to plant more eucalyptus trees, which are more resistant to rainfall variability as compared to annual crops such as wheat and teff. Similarly, more land triggers farmers to change crop varieties as adaptation strategy, mainly replacing local varieties by new varieties. Farmers with more land are less risk averse and therefore able to experiment with new crop varieties as compared to small-scale farmers.

\section{Farming experience (Farexp)}

Farming experience is found to be positively and significantly correlated with crop diversification at $p<0.05$. A unit increase in farming experience of a farmer increases the probability of using crop diversification by 1.97 times greater than those who have no farming experience. This is consistent with (Belay et al. 2017) who argued that farming experience helped to stimulate response to the negative effects of climate change on agriculture. This is because more experienced farmers are assumed to have better knowledge about weather information and its implication on agricultural adaptation practices.

\section{Income and Livestock holding}

The MNL model showed that, income of households has a positive and significant effect on the planting trees and off-farm activities (PTOFF) and has negative and significant effect on access to credit at $\mathrm{p}<0.1$ and $\mathrm{p}<0.05$ respectively. A unit increase in household income can increase the likelihood of planting trees and off-farm activities by 13.6 and decreases likelihood of using credit access by 0.61 . In the same way, livestock holding is positively and significantly associated with planting trees and off-farm activities at $\mathrm{p}<0.05$ and negatively correlated with credit. A unit increase in livestock increases the likelihood of planting trees and off-farm activities by 5.06. This is in line with (Adimassu and Kessler 2016) who noted that, the size of livestock and landholdings are directly or indirectly related to the household's financial endowments and positively influence farmers' capacities to cope and adapt to rainfall variability and reduction in crop yield. This implies that farmers with better financial resources have a better adaptation capacity.

\section{Access to extension (Ext) and credit services}

In Table 2, extension contacts have positive and significant correlation with crop diversification and growing improved and early maturing crops at $\mathrm{p}<0.01$ and $\mathrm{p}<0.1$ respectively. Similarly, access to credit services has positive association with all adaptation strategies. This finding confirms the works of (Hassan and Nhemachena 2008; Solomon et al. 2014; Temesgen 2008) who argued that, Better access to extension and credit services seems to have a positive influence on the probability of adopting all adaptation measures. Availability of credit eases the cash constraints and allows farmers to buy purchased inputs such as fertilizer, improved crop varieties and irrigation facilities. Access to extension services and trainings help farmers to take climate changes and weather patterns into account and help them on how to tackle to climatic variability and change. This might be due to improving skills, increasing awareness and realization of positive benefits from practicing different adaptation strategies after receiving formal and informal trainings.

\section{Access to Irrigation and water harvesting schemes (Irri)}

There is positive and significant relationship between access to irrigation and water harvesting schemes and crop diversification at $\mathrm{p}<0.01$. Having access to irrigation and water harvesting schemes increases the probability using crop diversification 8.09 times greater than those farmers who have no access to irrigation and water harvesting schemes. In the study area, there are only few farmers practicing irrigation farming from small rivers and underground water due to poor irrigation infrastructure. This is in line with (Belay et al. 2017) who noticed that, irrigation has been practiced in the area for vegetable production but its extent is still limited and also does not apply to field crops. This is associated with the inability of farmers to use both surface and ground water due to limited technological and financial capacity and they mentioned that underground water tables were receding progressively and they needed to dig deeper beyond $15 \mathrm{~m}$, which needed specialized equipment and technology which is beyond their reach. According to Hassan and Nhemachena (2008), more rainfall reduces the probability of choosing irrigation. The influence of changes in the summer-fall precipitation is stronger than that of changes in winter precipitation on the probability of switching away from mono-cropping. As most of the farming systems in Africa rely on rainfall, increased precipitation would be beneficial to dry land crop systems. Alternatively, low rainfall in all seasons induces the need for irrigation to buffer the negative impacts on agricultural production 
during dry periods. At the same time, limited rainfall also implies reduced availability of water for irrigation and it is important for policies to support efficient and effective irrigation systems. Nevertheless, the results suggest that the influence of warming on the probability of switching to more adapted systems is more powerful than the influence of changes in rainfall.

\section{Perception to climate change and variability (Per-ccv)}

Adaptation to climate change is a two-step process which requires that farmers perceive climate change in the first step and respond to changes in the second step through adaptation (Deressa et al. 2011). Perception guides decision making and eventually determines the actions to be made by farmers on climate change adaptation. The fact that, climate has been changing in the past and will continues to change in the future implies the need to understand how farmers perceive climate change and adapt in order to guide strategies for adaptation in the future (Tesfaye 2017). The Results of the MNL regression analysis show that, Perception to climate change and variability has positive and significant correlation with crop diversification, growing improved and early maturing crops and planting trees and off-farm activities at $1 \%, 5 \%$ and $1 \%$ levels of significance respectively. farmers' who perceived Changes and variability in climate are more likely to adapt through crop diversification, growing improved and early maturing crops and planting trees and off-farm activities by $0.19,0.2$ and 0.35 times greater when compared to those who do not perceived climate change and variability. This finding is supported by (Hassan and Nhemachena 2008) who stated that, farmers who noticed and aware of changes in climate would have higher chances of taking adaption measures that help them to reduce losses or take advantage of the opportunities associated with climate change and variability.

\section{Conclusion}

The results of the study showed that, majority of farmers have perceived increase in average temperature, decrease in the amount of seasonal rainfall and experienced the effects of a changing climate. These perceptions triggered farmers to adapt by using crop diversification, growing improved and early maturing crops, planting trees and engaging on off-farm activities, credit and taking loss. Farmers' choice of adaptation measures are influenced by different explanatory variables. Results from the MNL model analysis shows that out of 13 explanatory variables, 12 were found to be significant at $\mathrm{p}$-value less than $1 \%, 5 \%$ and $10 \%$. agro ecology of woina dega, age, sex, family size, farming experience, access to extension services, farm size, Irrigation and Perception to climate change and variability are significantly and positively associated with crop diversification while education, access to extension services and Perception to climate change and variability have positive and significant influence on growing improved and early maturing crops. On the other hand, farm size, income, education, livestock holding (TLU) and Perception to climate change and variability have significant and positive correlation with planting trees and offfarm activities. Similarly, income significantly and negatively influences the use of credit. Based on the analysis of socio-economic and environmental constraints to farmers' adaptation, Future climate change adaptation policies and strategies should build on existing adaptation strategies and should focus on creating awareness on climate change, livelihood diversification, improving agricultural extension services, small-scale irrigation and water harvesting technologies and promoting a transition to climate-smart agriculture.

\section{References}

Adimassu Z, Kessler A (2016) Factors affecting farmers' coping and adaptation strategies to perceived trends of declining rainfall and crop productivity in the central Rift valley of Ethiopia. Environ Syst Res 5:13. DOI $10.1186 / \mathrm{s} 40068-016-0065-2$

Arragaw A, Woldeamlak B (2017) Smallholder farmers' coping and adaptation strategies to climate change and variability in the central highlands of Ethiopia, Local Environment, 22:7, 825839,DOI:10.1080/13549839.2017.1290058

Atinkut B, Mebrat A (2016) Determinants of farmer's choice of adaptation to climate variability in Dera woreda, south Gondar zone, Ethiopia. Environ Syst Res 5:6. DOI 10.1186/s40068-015-0046-x

Belaineh L, Yared A, Woldeamlak B (2004) Smaller holder farmers' perceptions and adaptation to climate variability and climate change in Doba district, west Hararghe, Ethiopia. Asian J Empir Res 3(3):251-265

Belay A, Recha J, Woldeamanuel T, Morton J (2017) Smallholder farmers' adaptation to climate change and determinants of their adaptation decisions in the Central Rift Valley of Ethiopia. Agric \& Food Secur 6:24. DOI 10.1186/s40066-017-0100-1

CSA (2007) Central Statistical Agency: Population and Housing Census of Ethiopia, Result at national level, Statistical Report, Addis Ababa, Ethiopia.

Deressa TT, Hassan RM, Ringler C (2011) Perception of and adaptation to climate change by farmers in the Nile basin of Ethiopia. J Agric Sci 149(01):23-31.

Grace M (2011) Factors affecting perceptions and responsiveness to climate variability induced hazards; Msc thesis, University of Zimbabwe 
Hassan R, and Nhemachenas C (2008) 'Determinants of African farmers 'e strategies for adapting to climate change: multinomial choice analysis. African Journal of Agricultural and Resource Economics 2 (1): pp. 83-104.

Jiri O, Mafongoya P, Chivenge P (2015) Smallholder Farmer Perceptions on Climate Change and Variability: A Predisposition for their Subsequent Adaptation Strategies. J Earth Sci Clim Change 6: 277. doi:10.4172/21577617.1000277

Kide G (2014) Smallholder Farmers' Adaptation Strategies to Climate Change in Ethiopia: Evidence from Adwa Woreda of Tigray Region; MA thesis, Mekelle University

Leta A (2011) Assessment of climate change effects on rain fed crop production and coping mechanisms: the case of smallholder farmers of West Shoa Zone, Oromia, Ethiopia; Msc thesis, Addis Ababa University.

MoFED (2006). Ethiopia building on progress: A plan for accelerated and sustainable development to end poverty. Ministry of Finance and Economic Development, Addis Ababa, Ethiopia

Mohammad A (2007) Factors affecting employment choices in Rural Northwest Pakistan University of KasselWitzenhausen and University of Gottingen. Conference on International Agricultural Research for Development. October 2007. Ababa, Ethiopia.

Oremo F (2013) SMALL-SCALE FARMERS' PERCEPTIONS AND ADAPTATION MEASURES TO CLIMATE CHANGE IN KITUI COUNTY, KENYA; MA thesis, University of Nairobi, Kenya

Solomon B, Jones A, Stephen A (2014) Determinants of Adoption Choices of Climate Change Adaptation Strategies in Crop Production by Small Scale Farmers in Some Regions of Central Ethiopia. Journal of Natural Sciences Research Vol.4, No.4

Temesgen D (2008) Analysis of perception and adaptation to climate change in Nile basin of Ethiopia, by Post graduate Student at the Centre for Environmental Economics and Policy for Africa (CEEPA), University of Pretoria

Tesfaye S (2017) Farmers' Perception on Climate Variability and Change and Its Implication for Implementation of Climate-Smart Agricultural Practices in Geze Gofa District, Southern Ethiopia. Journal of Economics and Sustainable Development Vol.8, No.5

WMO (2007) The Role of world metrological organization in the implementation of the Nairobi Work Programme 